\title{
Adenocarcinoma of the Duodenum Arising in a Villous Adenoma
}

\author{
Paul C. Hessler and Ethan Braunstein \\ Department of Radiology, University of Michigan Medical Center, Ann Arbor, Michigan, USA
}

\begin{abstract}
Duodenal villous adenomas are premalignant lesions. Prior to malignant transformation, their appearance on upper gastrointestinal examination is often characteristic. Following malignant change, the final diagnosis frequently requires tissue.
\end{abstract}

Key words: Duodenum - Villous adenoma - Malignant potential - Adenocarcinoma.

Since Golden described a villous adenoma of the duodenum in 1928 [1], fewer than 50 cases have been described in the world literature $[2,3,4]$. Of these about a quarter had undergone malignant transformation into invasive carcinoma. The present case illustrates the clinical and radiologic aspects of adenocarcinoma arising in a villous adenoma of the duodenum in hopes of facilitating its earlier diagnosis.

\section{Case Report}

A 70-year-old woman was admitted to Danbury Hospital in June, 1974 , with a 16-year history of gradually worsening postprandial right upper quadrant pain, nausea, and vomiting suggesting partial gastric outlet obstruction. A suboptimal radiologic examination of the upper gastrointestinal tract in 1956 had shown a non-specific irregularity of the medial aspect of the supra-ampullary duodenum, but these findings were not pursued, and the patient had improved after learning to eat frequent, small meals. Repeated subpotential upper gastrointestinal examinations in 1970 and 1973 showed no change in the duodenal irregularity. In March, 1974, the patient's obstructive symptoms worsened, and she developed anemia and weight loss. At this time upper gastrointestinal examination demonstrated a polypoid tumor partially obstructing the supra-ampullary duodenum in the same area as the previously demonstrated duodenal irregularity. The patient refused treatment and was placed on a liquid diet with fair results. In June, 1974, her obstructive

Address reprint requests to: Paul C. Hessler, M.D., Dept. of Nuclear Medicine, Tufts-New England Medical Center, 171 Harrison Ave, Boston, MA 02111, USA symptoms became acute, she developed epigastric pain boring through to the back, and she was admitted.

Physical examination showed right upper quadrant tenderness and a palpable mass. There was a mild microcytic anemia, but electrolyte and liver function studies were normal. Gastroscopy was unsuccessful. Reexamination of the upper gastrointestinal tract redemonstrated the tumor (Figs. 1 and 2), and the patient was operated upon. A polypoid villous adenoma was found arising from the medial duodenal wall above the ampulla of Vater. The upper portion had undergone malignant transformation and had invaded the head of the pancreas. Two of eight peripancreatic lymph nodes were involved, but the liver was free of tumor. A pancreaticoduodenectomy was performed, but the patient developed a pancreaticocutaneous fistula and an epigastric abscess and died in septic shock on the 20 th postoperative day.

\section{Discussion}

Duodenal tumors are usually diagnosed when they obstruct the lumen, bleed from their friable surfaces, or obstruct the common bile duct. Of the 46 duodenal villous adenomas reported to date $[2,3,4], 19$ presented with gradually progressing luminal obstruction, and 23 had associated blood loss. Malignant tumors were especially likely to present with both pain and obstruction. Fifty-four of the 77 adenocarcinomas of the small bowel studied by Good [5] presented with both pain and obstruction. Our patient's anemia became apparent four months before her tumor was diagnosed, although she was not actively bleeding when examined. It is interesting that 22 of the 28 villous adenomas of the colon and rectum surveyed by Bacon also bled [6].

In 1930, Waters [7] made the first preoperative diagnosis of a benign duodenal villous adenoma, differentiating it from a polypoid adenoma by the multilocular filling defects produced by barium caught between the villous fronds. This characteristic appearance has become known as the 'soap bubble' or 'mousse de savon' sign and is often useful in diagnosing villous tumors throughout the gastrointestinal 


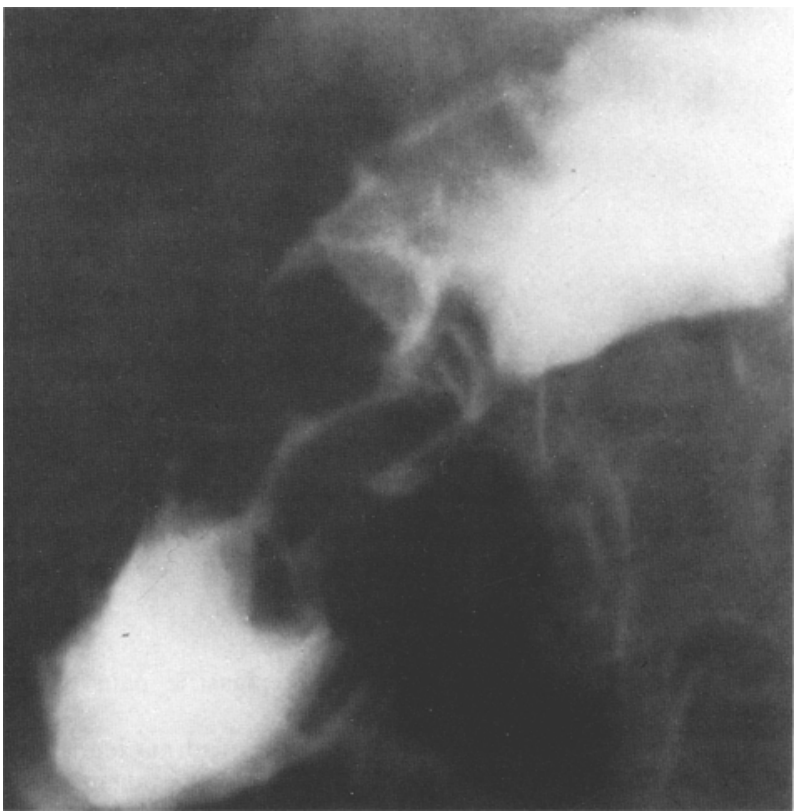

Fig. 1. Early filling film of the first and second portions of the duodenum demonstrating partial obstruction by a polypoid mass

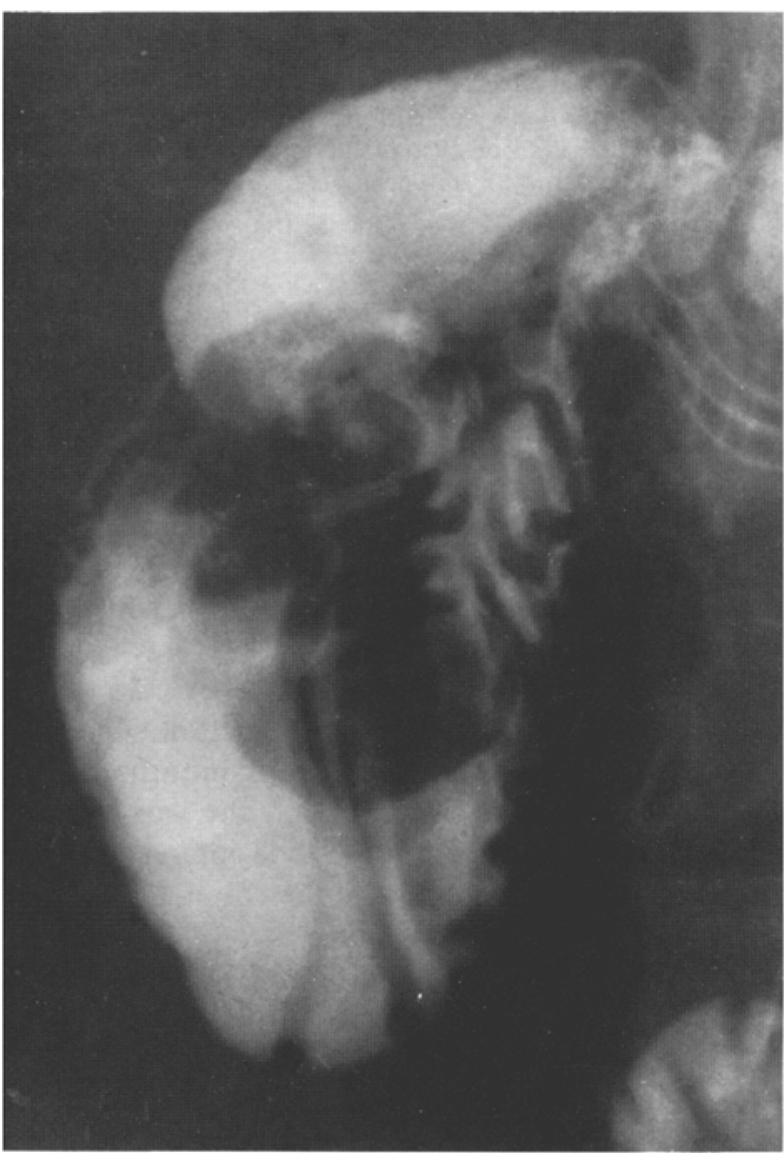

Fig. 2. Filled film of the first and second portions of the duodenum showing a polypoid filling defect arising from the medial wall tract. If our patient's villous adenoma had been evaluated with more meticulous fluoroscopic and spot film examination, supplemented perhaps by compression films and hypotonic duodenography, it is doubtful that she would have gone undiagnosed for 16 years as she did. By the time we examined her, the villous tumor had undergone malignant transformation and presented as a mass obstructing the duodenum, so that, in addition to a polypoid adenocarcinoma arising from the duodenal wall, several other diagnoses were entertained: ulcerated annular pancreas, pancreatic carcinoma invading the duodenum, chronic post-bulbar ulcer, and primary granulomatous disease of the duodenum.

The rate of malignant transformation in the 46 villous adenomas of the duodenum reported to date was about $36 \%$, somewhat less than the rate in the colon and rectum (55\%) reported by Enterline et al. [8], but still definitely establishing the premalignant nature of villous gastrointestinal tumors regardless of location.

Acknowledgments. The authors wish to thank William Martel, M.D., and Kyung Cho, M.D., for their helpful advice.

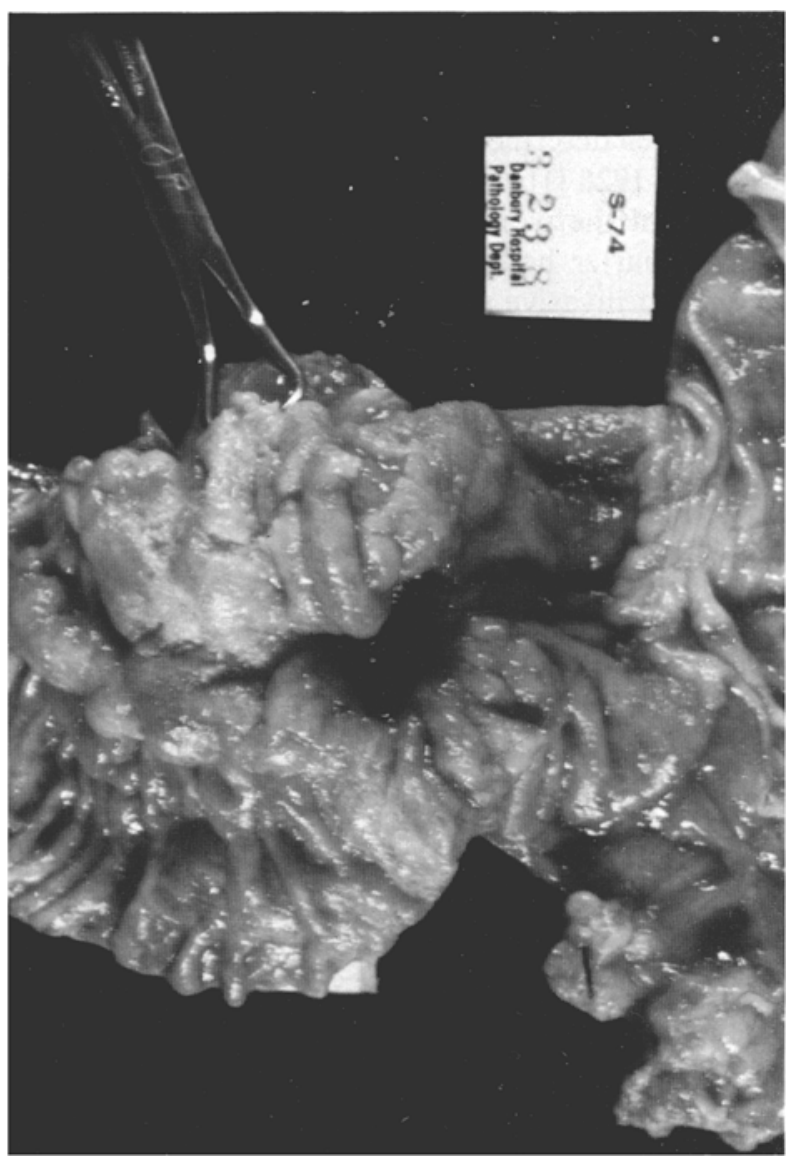

Fig. 3. Gross specimen of the opened duodenum showing a polypoid villous adenoma with malignant transformation on its superior border 


\section{References}

1. Golden R: Non-malignant tumors of the duodenum. Am $J$ Roentgenol Radium Ther Nucl Med 20:404-415. 1928

2. Perttala Y, Sonck S: Roentgenologically diagnosed benign polypoid adenoma of the duodenal bulb. Ann Med Int Fenn 54: $25-27,1965$

3. Jones PE. Clegg JF: Villous adenoma in a blind duodenal loop. Postgrad Med J 49:657-660, 1973

4. Schulten, MF Jr, Oyasu R, Beal JM: Villous adenoma of the duodenum: A case report and review of the literature. $A m J$ Surg 132:90-96, 1976
5. Good CA: Tumor of the small intestine, Caldwell Lecture 1962 Am J Roentgenol Radium Ther Nucl Med 89:685-705, 1963

6. Bacon HE, Lowell EJ Jr, Trimpi HD: Villous papillomas of the colon and rectum - a study of 28 cases with end results of treatment over a five-year period. Surgery 35:77-87, 1954

7. Waters CA: The roentgenologic diagnosis of papilloma of the duodenum. Am I Roentgenol Radium Ther Nucl Med 23:554-557. 1930

8. Enterline HT, Evans GW, Mercado-Lugo R, Miller L, Fitts WT: Malignant potential of adenomas of colon and rectum JAMA 179:322-330, 1962

Received: Julv 5, 1977; accepted: August 2, 1977 